\title{
ON INTEGRAL TRANSFORMS
}

\author{
K.C. GUPTA \\ Department of Mathematics \\ M.R. Engineering College \\ Jaipur-302004 \\ INDIA \\ (Received September 19, 1979)
}

ABSTRACT. A number of interesting theorems have recently been added to the existing ones in the field of integral transforms. The new arrivals can be broadly classified under two categories. The first expresses relationship between images and originals of related functions in the transforms concerned while the second reveals interconnections existing between images of related functions in the respective transforms. An attempt has been made in this paper to unify and extend all such results by establishing two most general theorems, embracing each of the two types mentioned above, and ufelucidate their basic underlying principle. Certain special cases of these theorems which are of interest in themselves and do not seem to be recorded in the literature have also been given. Exact reference to twenty four theorems which follow as simple special cases of our theorems has also been given.

KEY WORDS AND PHRASES. Integral Transforms, Laplace Transform, the H-function. 1980 MATHEMATICS SUBJECT CLASSIFICATION COOES: Primary 44A15, 44A10, $44 A 20$. Secondary $33 A 35$. 


\section{INTRODUCTION.}

The linear integral transform $\mathrm{T}[\mathrm{f}(\mathrm{x}) ; \mathrm{p}]$ of the function $\mathrm{f}(\mathrm{x})$ is defined by the integral equation:

$T[f(x) ; p\rfloor=\int_{a}^{b} k(x, p) f(x) d x=\emptyset(p) \quad$ (say)

wherein the class of functions and the domain of $p$ are so prescribed that the integral exists. In $(1.1), k(x, p)$ is known as the kernel of the transform, $\emptyset(p)$ the image of $f(x)$ in the said transform, and $f(x)$ the original. The following important theorem which is an analogue of the wel1-known Parseval-Goldstein theorem will be required in the sequel.

If

$$
\mathrm{T}\left[\mathrm{f}_{1}(\mathrm{x}) ; \mathrm{p}\right]=\emptyset_{1}(\mathrm{p})
$$

and

$$
\mathrm{T}\left[\mathrm{f}_{2}(\mathrm{x}) ; \mathrm{p}\right]=\emptyset_{2}(\mathrm{p})
$$

then

$$
\int_{0}^{\infty} f_{1}(x) \emptyset_{2}(x) d x=\int_{0}^{\infty} f_{2}(x) \emptyset_{1}(x) d x
$$

provided that the various integrals involved in the theorem converge absolutely.

\section{THEOREM 1.}

If

$$
h_{1}(p)=T_{1}\left[h_{2}(x) g(x) ; p\right]=\int_{0}^{\infty} k_{1}(p x) h_{2}(x) g(x) d x
$$

and

$$
h_{2}\left(p^{\sigma}\right)=T_{2}[f(x) ; p]=\int_{0}^{\infty} k_{2}(p x) f(x) d x
$$

then

$$
h_{1}(p)=\sigma \int_{0}^{\infty} f(x) \emptyset(x, p) d x
$$

where

$$
\begin{aligned}
\emptyset(\mathrm{p}, \alpha) & =\mathrm{T}_{2}\left[\mathrm{x}^{\sigma-1} \mathrm{~g}\left(\mathrm{x}^{\sigma}\right) \mathrm{k}_{1}\left(\alpha \mathrm{x}^{\sigma}\right) ; \mathrm{p}\right] \\
& =\int_{0}^{\infty} \mathrm{k}_{2}(\mathrm{px}) \mathrm{x}^{\sigma-1} \mathrm{~g}\left(\mathrm{x}^{\sigma}\right) \mathrm{k}_{1}\left(\alpha \mathrm{x}^{\sigma}\right) \mathrm{dx}
\end{aligned}
$$

provided that the integrals involved in the equations (2.1) to (2.4) are absolutely convergent, $\alpha$ is independent of $p$, and $\sigma$ is a non-zero real number.

PROOF. Applying generalized Parseval-Goldstein formula given by (1.2) to 
operational pairs given by (2.2) and (2.4), we get

$$
\int_{0}^{\infty} x^{\sigma-1} g\left(x^{\sigma}\right) k_{1}\left(\alpha x^{\sigma}\right) h_{2}\left(x^{\sigma}\right) d x=\int_{0}^{\infty} \emptyset(x, \alpha) f(x) d x
$$

Now, replacing $\alpha$ by $p$ in (2.5), changing the variable of integration slightly on its left-hand side and interpreting the result thus obtained in terms of (2.1), we easily arrive, after a little simplification, at the required result (2.3).

The above theorem is general in nature and generalizes a large number of interesting theorems given from time to time by several authors lying scattered in the literature. Thus, on making suitable choices of transforms $\mathrm{T}_{1}, \mathrm{~T}_{2}$, function $g(x)$ and the quantity $\sigma$ in $i t$, we easily get the theorems obtained earlier by Agarwal [1, p. 538], Bose [3, p. 59], Kaushik [10, p. 77, Jaiswal [9, p.85], Kesarwani [11, p. 298], Sharma [22, p.114], K.M. Saksena [16, p.1027, Arya [. 2, p.40], R.K. Saxena [18, p.404]. Gupta [6, p.3], Varma [26, p. 204], Srivastava and Vyas [23, p. 140], Mittal [14, p.33], Koul [12, p.14], S.K. Srivastava [24, p. 617 , and many others as special cases of Theorem 1 .

THEOREM 1(a). If in Theorem 1, we put $\sigma=1$ and take both the transforms $\mathrm{T}_{1}$ and $\mathrm{T}_{2}$ as Laplace transforms, $\phi(\mathrm{p}, \alpha)$ occurring in (2.4) can be given in a slightly altered form with the help of a known property of Laplace transform. In such a case we have (for $\sigma=1$ )

$$
\emptyset(\mathrm{p}, \alpha)=\mathrm{L}\left[\mathrm{g}(\mathrm{x}) \mathrm{e}^{-\alpha \mathrm{x}} ; \mathrm{p}\right]=\theta(\mathrm{p}+\alpha)
$$

where $\theta(p)=L[g(x) ; p]$ and the theorem assumes the following form:

If

$$
h_{1}(p)=L\left[g(x) h_{2}(x) ; p\right]=\int_{0}^{\infty} e^{-p x} g(x) h_{2}(x) d x
$$

and

$$
h_{2}(p)=L[f(x) ; p]=\int_{0}^{\infty} e^{-p x} f(x) d x
$$

then

$$
h_{1}(p)=\int_{0}^{\infty} f(x) \theta(x+p) d x
$$

${ }^{\text {where }} \theta(\mathrm{p})=\mathrm{L}[\mathrm{g}(\mathrm{x}) ; \mathrm{p}]=\int_{0}^{\infty} \mathrm{e}^{-\mathrm{px}} \mathrm{g}(\mathrm{x}) \mathrm{dx}$,

$\operatorname{Re}(p)>0$, and the various integrals involved in equations (2.6) to (2.9) are absolutely convergent.

Theorem 1(a) is of interest in itself. It is also quite general in nature 
and generalizes the theorems established earlier by Saxena $[19$, p.230], Malco $[13, \mathrm{p} .844]$, Saxena and Gupta $[21, \mathrm{p} .160]$ and several other authors.

\section{THEOREM 2}

If $h_{1}(p)=T_{1}\left[x^{(c / \sigma)-1} f(x) ; p\right]=\int_{0}^{\infty} k_{1}(p x) x^{(c / \sigma)-1} f(x) d x$

and

$$
h_{2}(p)=T_{2}\left[f\left(x^{-\sigma}\right) ; p\right]=\int_{0}^{\infty} k_{2}(p x) f\left(x^{-\sigma}\right) d x
$$

then

$$
h_{1}(p)=\sigma \int_{0}^{\infty} h_{2}(x) \emptyset(x, p) d x
$$

where

$$
\mathrm{p}^{-\mathrm{c}-1} \mathrm{k}_{1}\left(\alpha \mathrm{p}^{-\sigma}\right)=\mathrm{T}_{2}[\phi(\mathrm{x}, \alpha) ; \mathrm{p}]
$$

$\sigma$ is a non-zero real number, $\alpha$ is independent of $p$ and the integrals involved in the equations (3.1) to (3.4) are absolutely convergent.

PROOF. The above theorem easily follows on applying (1.2) to the pairs given by (3.2) and (3.4) and proceeding on lines similar to those indicated in the proof of Theorem 1 .

Theorem 2 given above is also sufficiently general in nature to generalize a number of theorems scactered in the literature on making suitable choice of transforms $T_{1}, T_{2}$, and $\sigma$ in it. Thus theorems obtained earlier by Bose [4, p. 18], Fiwari [25, p. 33], Rathie [15, p. 385], Saxena and Gupta [20, p. 712], Saxena [17, p. 166] and several others follow as special cases of this theorem.

Now we give below a special case of theorem 2 which is believed to be new and of interest in itself.

COROLLARY 1.

If $\quad h_{1}(p)=H\left[x^{(c / \sigma)-1} f(x) ; p\right]=\int_{0}^{\infty} x^{(c / \sigma)-1} f(x) H_{t, q}^{m, n}\left[p x \mid \begin{array}{l}\left(a_{j}, \alpha_{j}\right)_{1, t} \\ \left(b_{j}, \beta_{j}\right)\end{array}\right] d x$ (3.5) and

$$
h_{2}(p)=K\left[f\left(x^{-\sigma}\right) ; v ; p\right]=\int_{0}^{\infty}(p x)^{1 / 2} k_{v}(p x) f\left(x^{-\sigma}\right) d x
$$

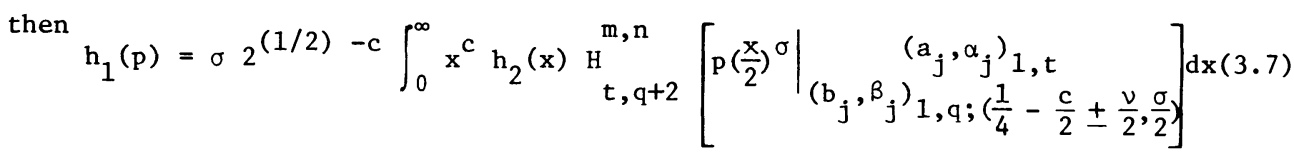
where the integrals involved in (3.5) to (3.7) are absolutely convergent, $\operatorname{Re}(p)>$ $0, \sigma>0$ and 
$-\sigma \min _{1 \leq j \leq m}\left[\operatorname{Re}\left(b_{j} / \beta_{j}\right)\right]<\min \operatorname{Re}(c \pm v+3 / 2)$.

PROOF. The above corollary follows from Theorem 2, if we take in it $T_{1}$ as the H-function transform defined by (3.5) (introduced by Gupta and Mittal [8, p.142]), $\mathrm{T}_{2}$ as the well-known Bessel function transform defined by (3.6) and make use of the following formula easily obtainable from the known results $[7$, Eq. (5.1), (4.4)

$$
\begin{aligned}
& \text { and (2.1)] }
\end{aligned}
$$

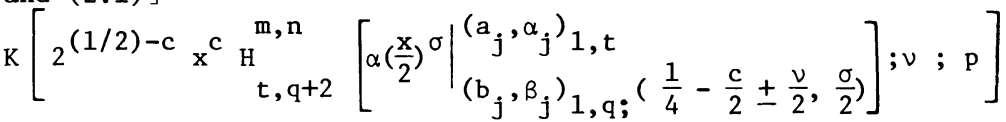

$$
\begin{aligned}
& =p^{-c-1} \mathrm{H}_{t, q}^{m, n}\left[\begin{array}{l|l}
\left.\alpha p^{-\sigma}\right|_{\left(b_{j}, \beta_{j}\right)} ^{\left(a_{j}, \alpha_{j}\right)} 1, t
\end{array}\right]
\end{aligned}
$$

The H-function occurring in the corollary stands for Fox's F-function. It is quite general in nature and includes most of the commonly used functions as its special cases. It is defined and represented as follows:

$$
\begin{aligned}
& \underset{t, q}{H^{m, n}}\left[x \mid \begin{array}{l}
\left(a_{j}, \alpha_{j}\right)_{1, t} \\
\left(b_{j}, \beta_{j}\right)_{1, q}
\end{array}\right]=\left[\begin{array}{l}
m, n \\
H_{t, q}
\end{array} \mid \begin{array}{l}
\left(a_{1}, \alpha_{1}\right), \ldots,\left(a_{t}, \alpha_{t}\right) \\
\left(b_{1}, \beta_{1}\right), \ldots,\left(b_{q}, \beta_{q}\right)
\end{array}\right]
\end{aligned}
$$

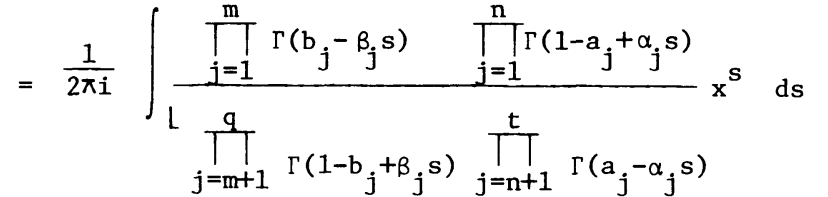

The nature of contour L, various conditions satisfied by its parameters for the convergence of the above integral and some of the special cases of the H-function can be referred to in the paper by Gupta and Jain [7].

If in Corollary 1, we reduce each of the transforms involved to Laplace transform, we get, after a little simplification a theorem obtained earlier by H.C. Gupta [5, p.140]. Several other theorems connecting different transforms can also be obtained from our corollary, by reducing the H-function transform involved in it to other simpler transforms mentioned by Gupta and Mittal [8]. We however omit the details.

ACKNOWLEDGMENT: The author is thankfu1 to the University Grants Commission, India for providing finaneial assistance. 


\section{REFERENCES}

1.. Agarwa1, R. P., "On Certain transformation Formulae and Meifer's G-function of Two Variables", Indian J. Pure Appl. Math. 1(1970), 537-551.

2. Arya, S.C., "Some Theorems Connected with a Generalized Stieltjes Transform," Bull. Calcutta Math. Soc. 51 (1959) 39-47.

3. Bose, S.K., "A Study of the Generalized Laplace Integral II," Bull. Calcutta Math. Soc. 41(1949) 59-67.

4. Bose, S.K., "A Note on Whittaker Transform," Ganita 1(1950) 16-22.

5. Gupta, H.C., "On Operational Calculus," Proc. Nat. Inst. Sci. India, Part A 3 (1948) 131-156.

6. Gupta, K.C., "Some Theorems on Integral Tranforms," Riv. Mat. Univ. Parma 2, $1-14$.

7. Gupta, K.C. and Jain, U.C., "The H-function II," Proc. Nat. Acad. Sci. India Sect. A 36 (1966) 594-609.

8. Gupta, K.C. and Mitta1, P.K., "The H-function Transform," J. Australian Math. Soc. 11 (1970) 142-148.

9. Jaiswal, J.P., "Two Properties of Meijer Transform," Ganita 3(1952) 85-90.

10. Kaushik, S.P., "A Theorem on the Generalized Laplace's Transform," Proc. Benaras Math. Soc. 8(1946) 7-10.

11. Kesarwani, R.N. (Roop Narain), " Some Properties of Generalized Laplace Transform-I," Riv. Mat. Univ. Parma 8(1957) 283-306.

12. Koul, C.I., "A Theorem Relating Generalized Hankel Transform and a Whittaker Transform," Math. Student 40(1972) 13-17.

13. Maloo, H.B., "Some Theorems in Operational Calculus II," Proc. Nat. Acad. Sci. India Sect. A 36(1966) 843-848.

14. Mittal, P.K., "Certain Properties of Meijer's G-function Transform Involving the H-function," Vijnana Parishad Anusandhan Patrika 14(1971) 29-34.

15. Rathie, C.B., "Some Properties of Generalized Laplace Transform," Proc. Nat. Inst. Sc1. India Part A 21 (1955) 382-393.

16. Saksena, K.M., "Generalizations of Stieltjes Transform," Bull. Calcutta Math. Soc. 45 (1953) 101-107.

17. Saxena, R.K., "A Theorem on Meijer Transform," Proc. Nat. Inst. Sci. India Part.A 25(1959) 166-170.

18. Saxena, R.K., "Some Theorems on Generalized Laplace Transform-I," Proc. Nat. Inst. Sci. India Part A 26 (1960) 400-413.

19. Saxena, R.K., "Some Theorems on Laplace Tranforms," Proc. Nat. Inst. Sci. India Part A $30(1964)$ 230-234.

20. Saxena, R.K. and Gupta, K.C., "Certain Properties of Generalized Stieltjes Transform Involving Meijer's G-function," Proc. Nat. Inst. Sci. India Part A 30 (1964) 707-714. 
21. Saxena, R.K, and Gupta, K.C., "On Laplace Transform," Riv. Mat. Univ. Parma 5 (1964) 159-164.

22. Sharma, K.C., "A Theorem on Meijer Transform and Infinite Integrals Involving G-function and Bessel Functions," Proc. Nat. Inst. Sci. India Sect. A 24(1958) 113-120.

23. Srivastava, H.M. and Vyas, O.D., "A Theorem Relating Generalized Hankel and Whittaker Transforms," Nederl. Akad. Wetensch. Proc. Ser. A 72 (1969) 140-144.

24. Srivastava, S.K., "Theorems on a Generalized Laplace Transform," Acta.Mexicana Ci. Tecn. 6(1972) 59-63.

25. Tiwari, N.D., "A Theorem in Operational Calculus," Proc. Benaras Math. Soc. 5 (1943) 33-36.

26. Varma, C.B.L., "On Some Properties of K-transform Involving Meljer's G-function, Proc. Nat. Acad. Sci. India Sect. A 28(1959) 200-207. 


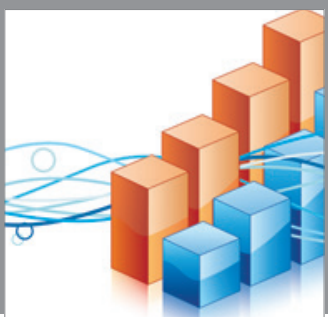

Advances in

Operations Research

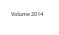

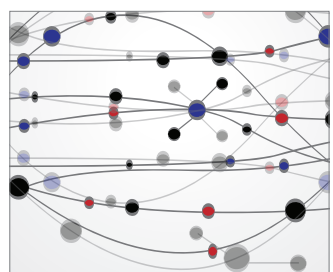

\section{The Scientific} World Journal
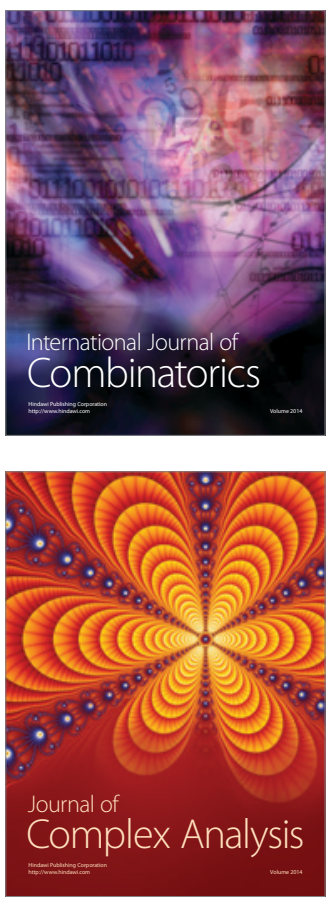

International Journal of

Mathematics and

Mathematical

Sciences
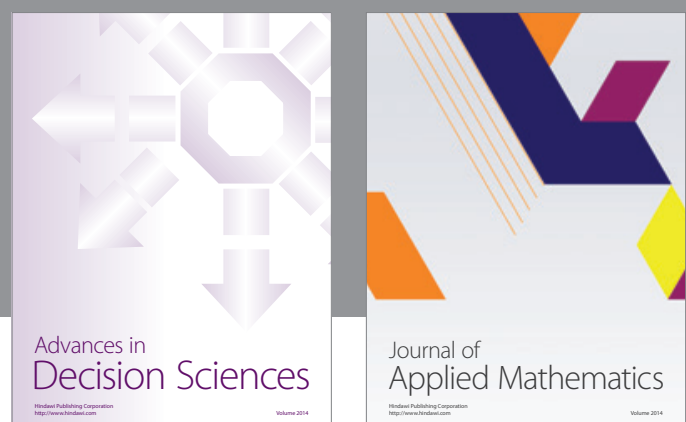

Journal of

Applied Mathematics
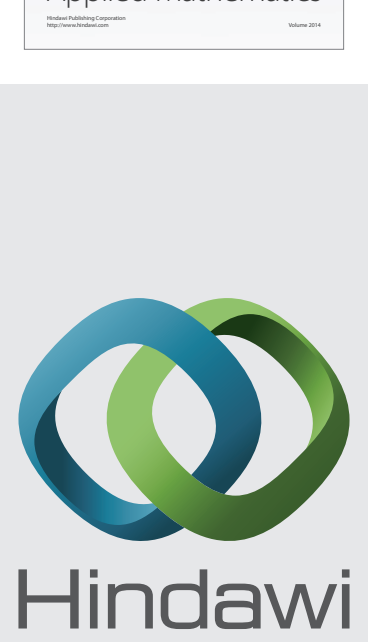

Submit your manuscripts at http://www.hindawi.com
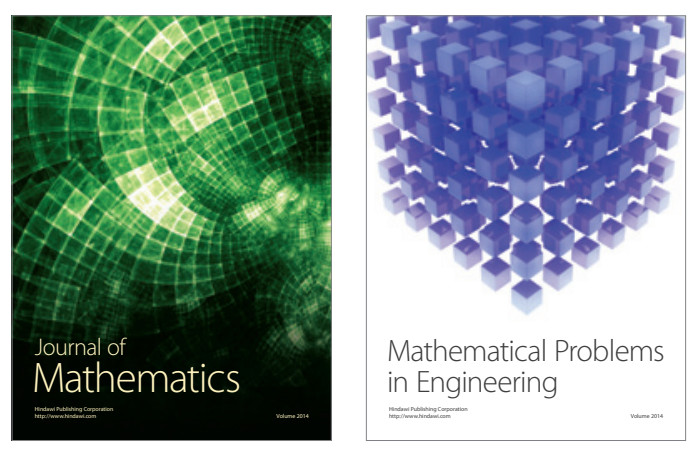

Mathematical Problems in Engineering
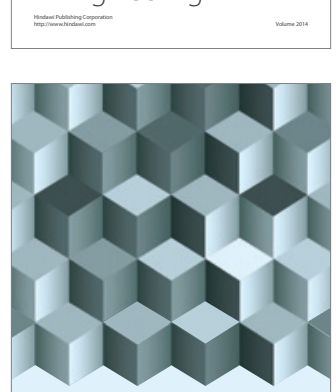

Journal of

Function Spaces
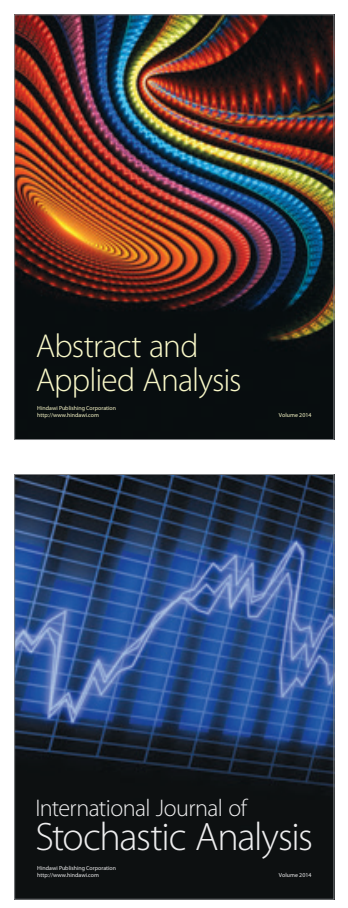

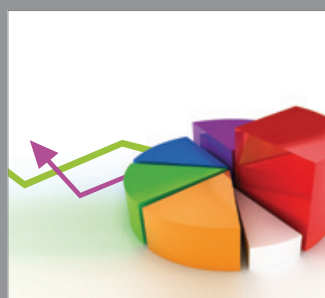

ournal of

Probability and Statistics

Promensencen
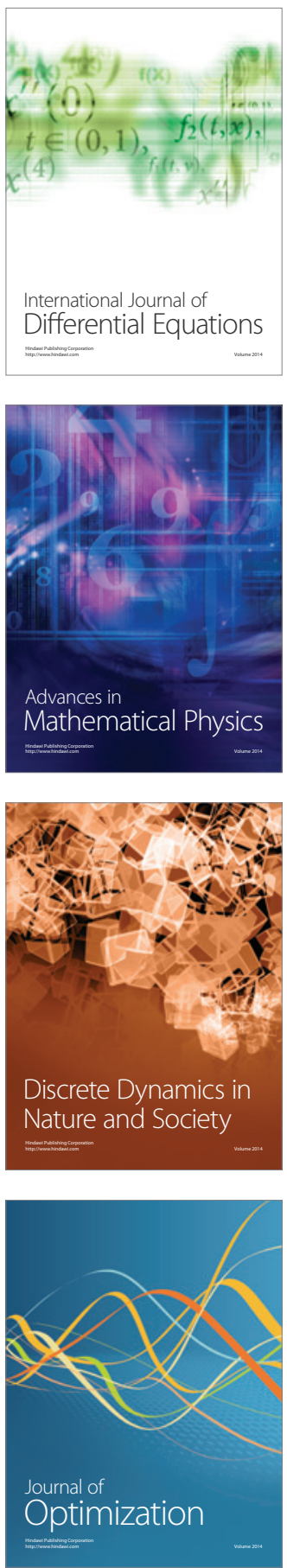